\title{
Fit-in GFRP Liner for Retrofitting Corroded Metal Culverts
}

\author{
Rahulreddy Chennareddy ${ }^{1}$, Susan Bogus Halter ${ }^{1}$, and Mahmoud M. Reda Taha, ${ }^{1, *}$ \\ ${ }^{1}$ Department of Civil, Construction and Environmental Engineering, University of New Mexico, Albuquerque, NM 87131-0001
}

\begin{abstract}
Corrugated metal pipes (CMPs) have been used as culverts in North America since the 1950s. Today, corrosion of CMPs is a major problem that requires an urgent and efficient solution to retrofit thousands of corroded CMPs across the country. One potential solution gaining wide acceptance is to use a fit-in Glass Fiber Reinforced Polymer (GFRP) liner inside the old CMPs and to connect them using polymer grout. In this paper, a methodology to retrofit corrugated metal culvert using a fit-in GFRP profile liner was developed and implemented. First, material characterization of the GFRP material and the epoxy grout were carried out for proper design of the retrofit system. Second, full-scale CMP-GFRP composite section was tested under three-point bending configuration to observe the retrofitted culvert behavior to failure. The new CMP-GFRP section develops full composite action and shows failure capacity of 75 kip with a deflection of 3.52 in at the end of the test. Post failure of the polymeric grout, GFRP pipe failure was observed at midspan location starting on the tension side. A finite element model was developed to understand the behavior of the CMP-GFRP composite pipe and to allow for the efficient design of the proposed retrofitting system.
\end{abstract}

\section{Introduction}

Culverts are water structures that facilitate the smooth conveyance of water without affecting the flow of water into the surrounding ecosystem. Culverts are also critical for the stability of highway infrastructure and storm sewers [1]. Culverts are typically constructed using reinforced or prestressed concrete or corrugated metal pipes (CMPs). Ease of installation, low initial cost and ease of fabrication make CMPs common systems for culverts since early 1950's. CMPs are prefabricated using aluminum, aluminized or galvanized steel and then connected, using riveted, welded or lock seam connection [2]. Today, an epidemic corrosion of CMPs can be observed across North America. Environmental service conditions of the CMPs, i.e., moisture content in the backfill material, water retained after flow inside the culvert, and repeated wetting and drying in unsubmerged conditions, contribute to the continuous corrosion of CMPs [3]. Typically, metal culverts were designed for a life expectancy of 50 years. However, recent investigations indicated that corrosion could drop the life expectancy of those culverts below 30 years [4]. Numerous incidents on CMPs culvert failures because of corrosion are reported in the literature [4]. Such failure events are rather expensive. Installation cost of a new culvert is relatively high due to its possible disruption of service and potential closure of highways. Occasionally, those costs can be higher than the cost of rebuilding the culvert itself $[4,5]$. Therefore, retrofitting of existing culverts is more feasible because of the complexity involved with un-backfilling, deconstruction, reconstruction, associated traffic disruption, and delay costs.

Currently, culvert retrofit is carried out using two main techniques, i.e., slip lining and spray on lining. Slip lining is currently performed by inserting poly vinyl chloride (PVC) pipes or high-density polyethylene (HDPE) pipes with the help of slip rails and filling gaps between the host pipe and the new pipe using a grout. Though inserting PVC and HDPE pipes looks promising because of their corrosion resistance, the pipes are brittle in cold temperatures [6] and have relatively very low structural capacity. This can be an issue for retrofitting corroded CMPs that have lost most of their structural capacity due to corrosion.

Glass Fiber Reinforced Polymers (GFRP) have gained acceptance as a corrosion-free structural material over the past three decades. GFRP entertain high strength as much as steel and very high strength to weight ratio and is corrosion free. An extensive review of the use of GFRP for new construction and structural rehabilitation can be found elsewhere [7]. Standard design guidelines have been developed for new construction and rehabilitation of concrete structures using GFRP [8, 9]. Using GFRP to retrofit metal culverts is relatively new and very few investigations have been completed worldwide [3]. GFRP profiles have recently been used for pipeline applications, specifically for geothermal, drainage, industrial waste and sewage pipelines due to the corrosion free nature of the material. GFRP has become a desirable material because of the material's ability to resist corrosion in harsh environments [10]. Design life expectancy of GFRP

\footnotetext{
* Corresponding author: mrtaha@unm.edu
} 
ranges between 75-100 years thus enabling a good extension in retrofitted culverts life.

In this paper, a fit-in GFRP profile liner inside a CMP connected using epoxy grout was tested. A methodology to retrofit corrugated metal culvert using a fit-in GFRP profile liner was developed and implemented. First, material characterization of the GFRP material and the epoxy grout were carried out to identify material properties for proper design. Second, a detailed method was developed to fit in a GFRP profile liner inside a CMP and to connect them using polymer grout. Finally, a full-scale steel-GFRP composite section was conducted under three-point bending configuration to observe the structural behavior of the GFRP retrofitted CMP up to failure.

\section{Experimental methods}

A 90.0 in. long, 18.0 in. diameter, and 0.064 in. thick CMP was chosen for retrofitting and testing the proposed retrofitting technology in the laboratory. The choice was based on using a CMP similar to those available in the field and still possible to test its composite capacity in the lab. The CMP was acquired from Contech Engineered Solutions LLC. For the fit-in GFRP profile liner, a filament wound GFRP pipe section with a length of $90.0 \mathrm{in}$, diameter of $15.0 \mathrm{in}$. and thickness of $0.35 \mathrm{in}$. was fabricated and supplied by Sewer Shield Composites LLC to fit the chosen CMP dimension. The GFRP pipe has fibers orientation in \pm 45 degrees along the length of the beam. The GFRP section was fabricated using an amine-based epoxy. In order to have the best bond between GFRP and grout material, an amine-based epoxy grout was selected for the retrofit system. An amine based two-component epoxy system supplied by U.S. Composite, Inc., Palm Beach, FL was used along with silica filler to produce the grout material. The primary component of the epoxy system is a low viscous liquid epoxy resin 100\% reactive based on Bisphenol-A. The second component is an epoxy-hardener consisting of aliphatic amine. The resin to hardener mix ratio is $2: 1$ by weight. Silica based aggregate supplied by Transpo, Inc., NY, was used as the grout filler. The epoxy and filler material were mixed at 1:1 ratio by volume.

First, a wooden spacer was created inside the 18 in. diameter CMP to allow for concentrically sliding the GFRP liner and to prevent the filling grout from flowing outside the space between CMP and GFRP. The wooden spacer was bonded to the inner steel surface using a thickened epoxy paste. This wooden spacer was created on both ends of the CMP. A 1.0 in. diameter hole was core drilled in the CMP to insert a grout hose that was completely sealed using thickened epoxy. To achieve a good bond between GFRP and grout, the GFRP profile was surface grinded using an 80 -grit sheet sander. The GFRP profile was then completely washed off to remove any debris using a water jet and completely dried using compressed air. The GFRP pipe was then slid inside the CMP. Both ends were sealed using thickened epoxy to form an airtight seal.
Tension and compression testing of bi-directional GFRP composite was conducted. For each test, two types of specimens were tested, on- and off-axis test specimens. All testing was conducted based on ASTM D 3518 and ASTM D 3039 [11, 12]. All the tension tests were conducted using MTS ${ }^{\circledR}$ Bionex servo hydraulic system with 5.6-kip capacity with a cross head displacement rate of $0.08 \mathrm{in} . / \mathrm{min}$. The tension specimens were $0.5 \mathrm{in}$. wide, 7.0 in. long and 0.2 in. All the compression tests were performed using Forney ${ }^{\circledR}$ compression testing machine under displacement control mode using a cross head displacement rate of $0.015 \mathrm{in} . / \mathrm{min}$. The compression specimens were 3.0 in. long, 2.0 in. wide and $1.0 \mathrm{in}$. The grout material was tested under uniaxial tension and compression based on ASTM D638 and ASTM C469/C469M [13, 14]. A crosshead displacement rate of $0.04 \mathrm{in} . / \mathrm{min}$ for both tests.

A 3-point bending test was conducted on the CMP section retrofitted with GFRP profile liner. The experimental setup is presented in Figure 1.

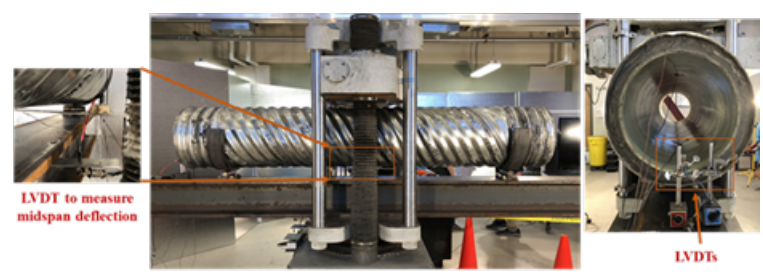

(a)

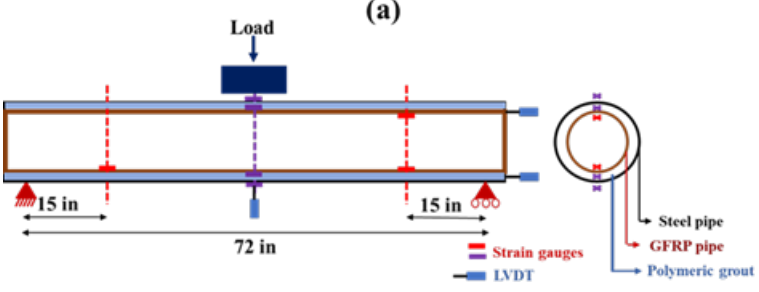

(b)

Fig. 1. (a) Experimental set-up for testing CMP retrofitted with GFRP profile liner under three-point bending; (b) Experimental instrumentation.

The test setup was designed with semicircular striped loading and reaction points to allow having one hinge support and one roller support. A 400-kip Instron loading frame with cross head displacement rate of 0.012 in./min was used to perform the test of the composite section. Linear Variable Displacement Transducers (LVDTs) were placed at mid span section to measure the deflection of the composite beam and at the end to observe any debonding and to measure the end slip between GFRP, grout material and CMP. The data was recorded at $10 \mathrm{~Hz}$ time period and the test continued for 5 hours and 6 minutes.

\section{Results and discussion}

The mechanical properties for GFRP and epoxy grout are presented in Table 1. The mechanical properties examined include Young's modulus of elasticity, tensile strength and modulus for on-axis $\left(0^{\circ}\right)$ and off-axis $\left(45^{\circ}\right)$ GFRP. The polymer grout behavior represents a typical 
behavior exhibited by polymer concrete under compression and tension stresses [15]. The load versus deflection behavior of the CMP-GFRP composite section is presented in Figure 2(a).

Table 1. Mechanical properties of GFRP and epoxy grout.

\begin{tabular}{|c|c|c|c|}
\hline Parameter & $\mathbf{0}^{\circ}$ GFRP & $\mathbf{4 5}^{\circ}$ GFRP & Grout \\
\hline $\begin{array}{c}\text { Tensile } \\
\text { strength (psi) }\end{array}$ & $54,289 \pm 4033$ & $5,479 \pm 651$ & $2,040 \pm 350$ \\
\hline $\begin{array}{c}\text { Tensile } \\
\text { modulus } \\
\text { (ksi) }\end{array}$ & $2,794 \pm 107$ & $1,088 \pm 184$ & $659 \pm 142$ \\
\hline $\begin{array}{c}\text { Compressive } \\
\text { strength (psi) }\end{array}$ & $15240 \pm 1200$ & $10720 \pm 200$ & $8392 \pm 421$ \\
\hline $\begin{array}{c}\text { Compressive } \\
\text { Modulus } \\
\text { (ksi) }\end{array}$ & NA & NA & $1,590 \pm 112$ \\
\hline
\end{tabular}

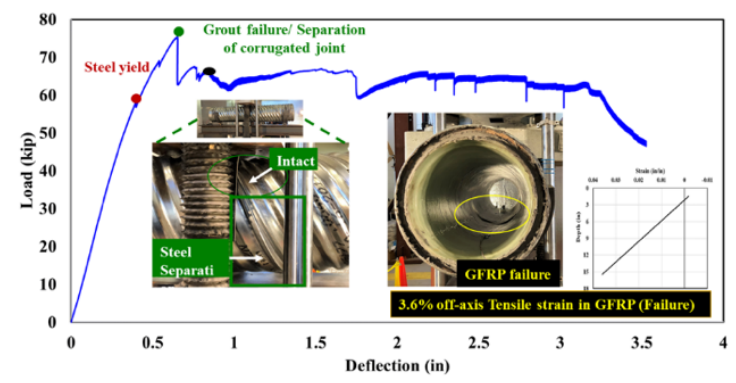

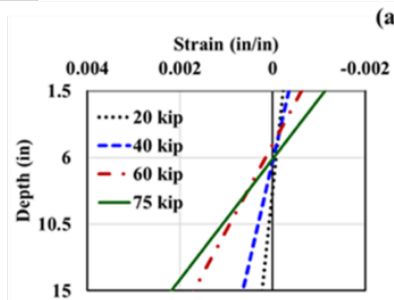

(b) (a)

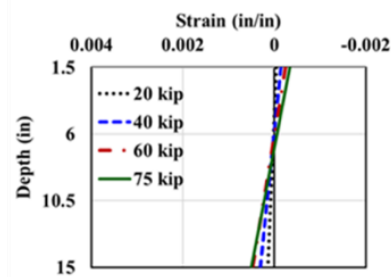

(c)

Fig. 2. (a) Load versus deflection behavior of steel-GFRP composite beam; (b) Strain profiles in GFRP at mid-span at different load levels (c) Strain profiles in GFRP at 15 in from support at different load levels.

The CMP-GFRP composite pipe was tested under threepoint bending configuration until the final deflection reached $3.52 \mathrm{in}$. This was the maximum deflection possible for the test configuration, so the test was terminated at that time. The composite section was able to observe higher deflection than that maximum reported here. The load versus deflection behavior exhibited a linear elastic behavior up to a load of 57.6 kip. At this force the strain data indicated that the steel started to yield with a strain reading of 0.0021 . After this point, the behavior was nonlinear until the peak load of 75 kip was reached. The load started to drop after reaching the peak load. The post peak behavior exhibited significant deformability until the test was stopped at maximum deflection of 3.52 in. while the CMP-GFRP system retained $62 \%$ of the peak load at $46.6 \mathrm{kip}$. The overall ductile behavior of the CMP retrofitted GFRP system can be attributed to the very ductile material behavior of the individual materials steel, polymer grout, off-axis

GFRP material, and the superior bond between both GFRP and steel to the polymer grout material.

The modes of failure of the CMP-GFRP section to the corresponding peak loads were identified and are shown in Figure 2. First, the point at which the steel yielded is shown. Second, failure mode at the peak load is shown. Failure at the peak load occurred because of separation of the CMP joint located exactly at the mid span section of the beam as shown in Figure 2(a). At the peak load of 75 kips, compression existed on top of the beam and maximum tension existed below the neutral axis at the bottom farthest location. At that load, the strains in GFRP reached -0.00113 the corresponding strain reading in GFRP in tension has been recorded as 0.0023 and post peak after the load drop, the strain in tension GFRP increased to 0.0072 , indicating a sudden increase in strain of GFRP under tension. No change in the compression strain maintaining at -0.00113 . This can be attributed to steel separation and tension failure of grout itself as the failure strain of grout in tension was 0.005 as shown in Figure 2(b). Beyond this point, the strains in GFRP increased significantly. At point (iii) shown in Figure 2(a) GFRP on the tension side started to fail as the strain in GFRP reached 0.036 in./in., which is very close to the typical off-axis failure strain in GFRP. Nevertheless, no signs of failure in compression were observed at this point of loading. The CMP joint separation and GFRP failure at the end of the test are shown in Figure 3.

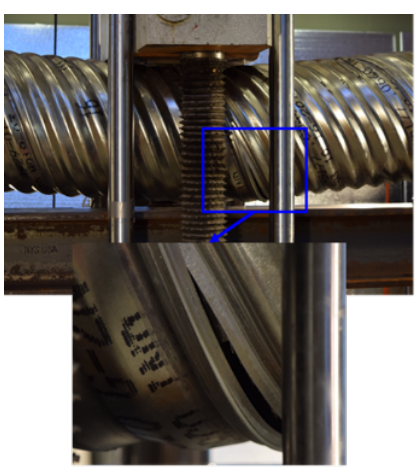

(a)

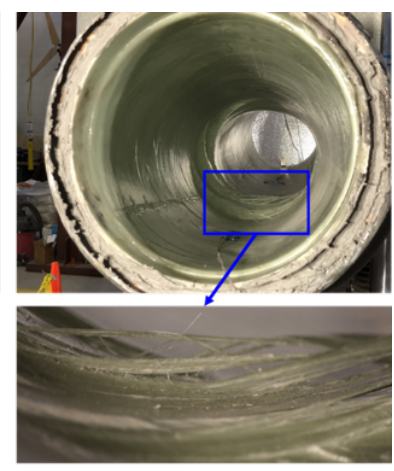

(b)
Fig. 3. (a) Corrugated steel pipe joint complete separation at the end of the test; (b) GFRP failure.

\section{Numerical simulation}

A commercial finite element software ABAQUS was used to model the CMP-GFRP composite section. The system was developed making use of the 3D geometry in ABAQUS. The model consists of steel circular pipe section, grout section and the GFRP pipe section. All the three materials were constrained with a tie constrain assuming perfect bond between GFRP-grout and steelgrout. A mesh size of approximately 2.0 in was used for the model. A C3D20R, a 20-node quadratic brick, reduced integration with quadratic geometric order was used for the analysis. Steel was modeled as elasticplastic material with a Youngs modulus of elasticity of 29,000 ksi and Poisson's ratio of 0.3. The grout material was model as isotropic material with tensile properties in Table 1. Concrete Damage Plasticity (CDP) model was 
used to model damage occurrence and propagation in the grout. Stress-strain of the grout material extracted from the material characterization stage were used in the FE model. A semicircular ring was used to represent the supports and loading head with boundary conditions similar to those used in testing. The model is shown below in Figure. 4(a). The load versus displacement behavior comparing experimental to the numerical analysis is presented in Figure 4(b). The behavior from numerical analysis agrees well with the experimental observations. Further work is underway to improve the finite element model and to use it for future design of the culvert retrofitting system.

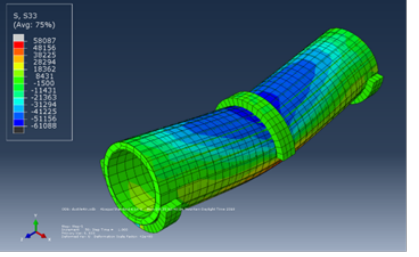

(a)

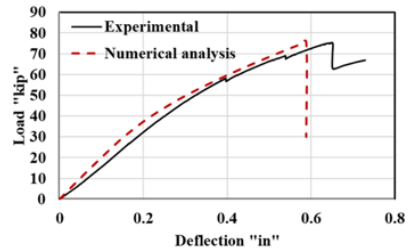

(b)
Fig. 4. (a) CMP-GFRP composite pipe numerical model; (b) Load versus deflection behavior of numerical model compared with that observed experimentally.

\section{Conclusions}

A new retrofitting technique using fit-in GFRP profile liner for CMPs used in culverts has been developed and tested. A fit-in GFRP liner was able to retrofit a CMP by sliding the GFRP liner and filling the gap with a polymer grout. The GFRP liner was surface prepared and slid inside the CMP. An epoxy grout was used to fill the gap. The CMP-epoxy grout-GFRP section was tested under static load to failure in three-point bending. The CMPGFRP composite section had a maximum load capacity of 75 kips. The primary mode of failure identified for the composite section is the separation of corrugated steel joint and grout failure in tension at $75 \mathrm{kip}$ and then rupture of the GFRP. GFRP failure only took place at the mid-span of the beam. For the rest of the beam the GFRP was intact. Analysis showed that the CMP-epoxy groutGFRP developed a full composite action until the peak load was observed. The load versus deflection behavior indicates a ductile composite section. A finite element model to simulate the behavior was developed and showed good agreement with the experimental observation. Further work is underway in modelling the progressive failure of GFRP-CMP to allow using the finite element method for design of the retrofitting system. A limitation of the above study is it was performed on a non-corroded CMP. GFRPs corrosion resistance and high specific strength to weight ratio can improve service life expectancy of in-service CMP culverts to additional 75 years.

\section{References}

1. Moser, A.P., and Folkman, S.L., Buried Pipe Design. McGraw-Hill, New York, 2001.

2. Sezen, H., Yeau, K.Y., and Fox, P.J., In-situ load testing of corrugated steel pipe-arch culverts.
Journal of Performance of Constructed Facilities, 22(4), 245-252, (2008).

3. Ehsani, M., Repair of corroded/damaged metallic pipelines using fiber-reinforced polymer composites. In Rehabilitation of Pipelines Using Fiber-reinforced Polymer (FRP) Composites, Elsevier, 39-59, (2015).

4. Perrin Jr, J., and Jhaveri, C.S., The economic costs of culvert failures. In Prepared for TRB 2004 Annual Meeting, Washington DC, (2004).

5. Wyant, D., Assessment and Rehabilitation of Existing Culverts. NCHRP Synthesis of Highway Practice No. 303. Transportation Research Board, Washington DC, (2002).

6. Wagener, B.D., and Leagjeld, E.E., Culvert repair best practices, specifications and special provisions: Best practices guidelines. In Department of Transportation, Research Services \& Library, (2014).

7. Bakis, C.E., Bank, L.C., Brown, V., Cosenza, E., Davalos, J., Lesko, J., Machida, A., Rizkalla, S., and Triantafillou, T., Fiber-reinforced polymer composites for construction-State-of-the-art review. Journal of Composites for Construction, 6(2), 73-87, (2002).

8. ACI 440.2R-17. A Guide for the Design and Construction of Externally Bonded FRP Systems for Strengthening Concrete Structures. American Concrete Institute, Farmington Hills, MI. (2017).

9. ACI 440.1R-15. A Guide for the Design and Construction of Structural Concrete Reinforced with Fiber-Reinforced Polymer Bars. American Concrete Institute, Farmington Hills, MI. (2015).

10. Hota, G., and Liang, R., Advanced fiber reinforced polymer composites for sustainable civil infrastructures. In Proceedings of the International Symposium on Innovation \& Sustainability of Structures in Civil Engineering, Xiamen University, (2011).

11. ASTM D3518/3518M-13. Standard Test Method for In-Plane Shear Response of Polymer Matrix Composite Materials by Tensile Test of a $\pm 45^{\circ}$ Laminate. ASTM International, West Conshohocken, PA. (2013).

12. ASTM D3039/3039M-14. Standard Test Method for Tensile Properties of Polymer Matrix Composite Materials. ASTM International, West Conshohocken, PA. (2014).

13. ASTM D638-14. Standard Test Method for Tensile Properties of Plastics. ASTM International, West Conshohocken, PA. (2014).

14. ASTM C469/C469M-14. Standard Test Method for Static Modulus of Elasticity and Poisson's Ratio of Concrete in Compression. ASTM International, West Conshohocken, PA. (2014).

15. Douba, A. Mechanical Characterization of Polymer Concrete with Nanomaterials. Masters Thesis, The University of New Mexico. (2017). 